\title{
The Role of Elasticity in the Anomalous Swelling of Polymer Thin Films in Density Fluctuating Supercritical Fluids
}

\author{
Tadanori Koga, ${ }^{*, \dagger}$ Y.-S. Seo, ${ }^{\dagger}$ K. Shin, ${ }^{\dagger}$ Y. Zhang, ${ }^{\dagger}$ M. H. Rafailovich, ${ }^{*, \dagger}$ \\ J . C. Sokolov, ${ }^{\dagger}$ B. Chu, ${ }^{\dagger, \S}$ and S. K. Satija\#
}

Department of Materials Science \& Engineering, State University of New York at Stony Brook, Stony Brook, New York 11794-2275; Department of Materials Science and Engineering,

K-J IST, Kwang-ju, 500-712 Korea; Department of Chemistry, State University of New Y ork at Stony Brook, Stony Brook, New York 11794-3400; and Center for Neutron Research, National Institute of Standards and Technology, Gaithersburg, Maryland 20899

Received August 5, 2002

\begin{abstract}
In situ neutron reflectivity was used to investigate the effects of density fluctuations on the solubility of supercritical carbon dioxide $\left(\mathrm{scCO}_{2}\right)$ in polymer thin films. Deuterated polystyrene, deuterated polybutadiene, and the corresponding random copolymer, deuterated styrenerandombutadiene copolymer, as well as deuterated poly(methyl methacrylate) were investigated. Data were obtained as a function of pressure under two isothermal conditions $\left(\mathrm{T}=36\right.$ and $\left.50{ }^{\circ} \mathrm{C}\right)$. All the polymer films used showed anomalous swelling and $\mathrm{CO}_{2}$ sorption on the density fluctuation ridge in the $\mathrm{P}-\mathrm{T}$ phase diagram of $\mathrm{CO}_{2}$. We found that the magnitude of the swelling was a function of the elasticity of the films rather than the bulk solubility of $\mathrm{CO}_{2}$. The enhanced miscibility of the rubber/CO $\mathrm{CO}_{2}$ systems, which are very poor in bulk, was found to be almost identical to that of the silicon rubber $/ \mathrm{CO}_{2} \mathrm{mixture}$, which is one of the highly miscible polymeric materials under moderate $\mathrm{CO}_{2}$ conditions.
\end{abstract}

\section{Introduction}

Over the past two decades, supercritical fluids (SCFs) have been tremendously utilized as a regeneration solvent in a wide range of technical and chemical processes. ${ }^{1}$ The unique features of SCFs are that the solvent quality of SCF s is pressure or/and temperature dependent, while the diffusion coefficient is closer to that of a gas. By varying the external parameters of temperature and pressure, one can control the interactions between the polymer and the fluid environment. In particular, much attention has been focused on supercritical carbon dioxide, $\mathrm{scCO}_{2}$, since $\mathrm{CO}_{2}$ has a moderate critical point with $\mathrm{T}_{\mathrm{C}}=31.3^{\circ} \mathrm{C}$ and $\mathrm{P}_{\mathrm{C}}=7.38$ $\mathrm{MPa}$ and is an environmentally clean solvent.

The other special characteristic of SCFs is large density fluctuations in these systems. According to the molecular dynamics simulation of a two-dimensional Lennard-J ones fluid, such fluctuations in pure solvent cause inhomogeneous regions of high and low density, which is represented by the correlation length, $\xi .{ }^{2}$ As the critical point of a fluid is approached, $\xi$ and the isothermal compressibility, $\kappa_{\mathrm{T}}$, diverge. ${ }^{3}$ Density fluctuations, $\left\langle(\Delta \mathrm{N})^{2}\right\rangle\left\langle\langle\mathrm{N}\rangle\right.$, are expressed by using $\kappa_{\mathrm{T}}$

$$
\left\langle(\Delta \mathrm{N})^{2}\right\rangle /\langle\mathrm{N}\rangle=(\mathrm{N} N) \kappa_{\mathrm{T}} \mathrm{k}_{\mathrm{B}} \mathrm{T}
$$

where $k_{B}$ is the Boltzmann constant and $T$ is the thermodynamic temperature. ${ }^{3}$ If the $\kappa_{T}$ values are known as a function of temperature and pressure, we can discuss the thermodynamic behavior in $\left\langle(\Delta N)^{2}\right\rangle\langle\hat{N}\rangle$ of SCFs. Figure la shows the $\left\langle(\Delta \mathrm{N})^{2}\right\rangle /\langle\mathrm{N}\rangle$ values of $\mathrm{CO}_{2}$ under the isobaric conditions near the critical point. To

\footnotetext{
† Department of Materials Science \& Engineering, SUNY.

₹ K-J IST.

$\S$ Department of Chemistry, SUNY

\# National Institute of Standards and Technology.

* Corresponding authors: e-mail tkoga@notes.cc.sunysb.edu; mrafailovich@notes.cc.sunysb.edu.
}
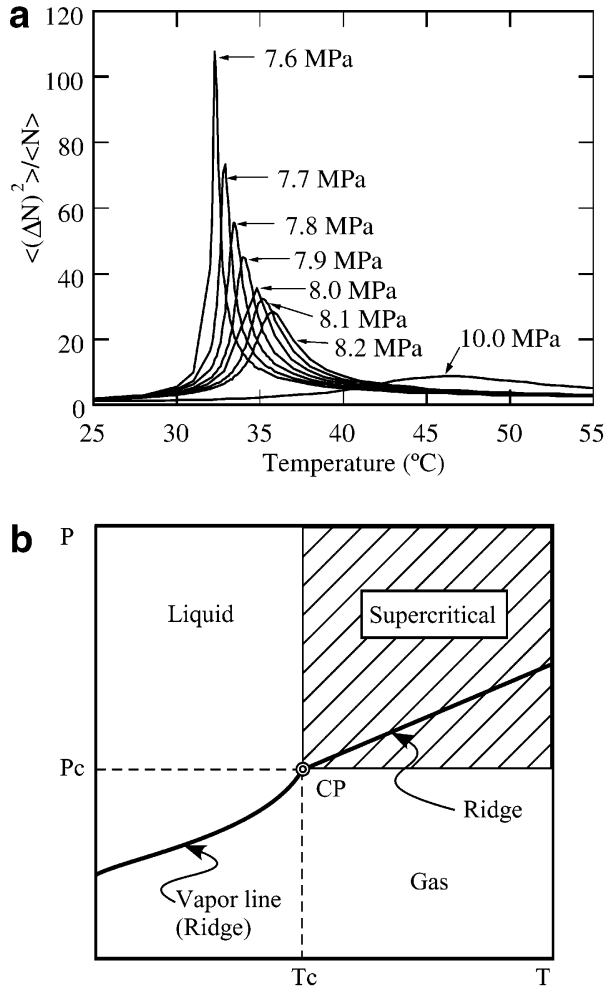

Figure 1. (a) Calculated density fluctuations using the equation of state of $\mathrm{CO}_{2}$. (b) Schematic phase diagram of $\mathrm{CO}_{2}$ near the critical point. Critical point is denoted as CP. Solid line represents the ridge of $\mathrm{CO}_{2}$ reported in ref 5.

obtain the $\kappa_{\mathrm{T}}$ values of $\mathrm{CO}_{2}$, we used the equation of state given by Huang et al. ${ }^{4}$ These calculated $\left\langle(\Delta N)^{2}\right\rangle /$ $\langle\mathrm{N}\rangle$ values are in good agreement with those previously reported from small-angle X-ray scattering measurements. ${ }^{5}$ From the figure we can see that the characteristic features of density fluctuations in the supercritical region are (i) there is a peak in each lateral curve, (ii) the amplitude of the fluctuation diverges as the critical 
point is approached, and (iii) the width of the peak broadens with increasing pressure. As shown in Figure $1 \mathrm{~b}$, the locus of the peaks in $\left\langle(\Delta \mathrm{N})^{2}\right\rangle /\langle\mathrm{N}\rangle$ curves forms the ridge of density fluctuations. The ridge is continuous across $T_{c}$ and separates the more liquidlike and more gaslike regions in the supercritical region.5,6 In the region below the critical point, the ridge corresponds to the vapor line. In the supercritical region, there is a memory of the vapor line; that is the ridge. This ridge is not specific to $\mathrm{CO}_{2}$ and is a general feature for the substances, such as $\mathrm{H}_{2} \mathrm{O}, \mathrm{CF}_{3} \mathrm{H}$, Ar, and $\mathrm{Hg}^{6}$

Thermodynamic properties of $\mathrm{scCO}_{2}-$ polymer phase systems, such as swollen volume, solubility, and viscosity, are very important in various polymer processing operations. Several groups reported the effects of temperature and pressure of $\mathrm{CO}_{2}$ on the swelling of bulk polymers, such as polystyrene (PS), ${ }^{7-9}$ poly(methyl methacrylate) (PMMA) $)^{7-10}$ and polycarbonates (PC),, 70 silicone rubber (SR), ${ }^{11-13}$ and poly(dimethylsiloxane) (PDMS), 14,15 in a range of sub- and/or supercritical regions. The typical features of bulk swelling and solubility data show an "S"-shaped isotherm with an inflection point in the vicinity of $P_{c}$. The thermodynamics of the bulk polymer-supercritical mixtures have been successfully described by the lattice models, such as the Sanchez-Lacombe (S-L) equation of state or the Panayiotou-Vera equation of state, which holes or vacancies have been introduced to simulate the effect of the change in volume. ${ }^{7,8,14-16}$

On the other hand, very little is known about the interaction of $\mathrm{CO}_{2}$ with polymer thin films, which are of significant technological importance in coating, lubrication, and adhesion. The behavior of $\mathrm{CO}_{2}$ with polymer thin films may differ from that in the bulk, since one must also consider the effect of surface interactions and confinements. It is well-known that the presence of an interacting surface can also modify the physical properties of thin films such as viscosity, diffusion coefficient, and possibly glass transition temperature. ${ }^{17}$ The introduction of a third component, such as a solvent that can compete with the polymer for adsorption to the surface, introduces yet another variable in determining the properties of thin films. The technical difficulties involved in delivering the probe beams, such as neutron and laser beams, into high pressure vessels have only recently been overcome. By using in situ neutron reflectivity (NR), we clarified that the large density fluctuations of $\mathrm{CO}_{2}$ enhanced the swelling of polymer thin films at the density fluctuation ridge even when the bulk miscibility of the polymer with $\mathrm{CO}_{2}$ was very poor. ${ }^{18}$ Because of its large penetration depth, NR is an ideal technique to determine the in situ thickness, composition, and interfacial structure of polymer thin films immersed in fluids or gases, under high pressure in thick walled vessels. The functional form of the dilation amplitude followed that of the calculated density fluctuations as a function of temperature and pressure. Sirard et al. reported the swelling behavior of PDMS and PMMA thin films in contact with $\mathrm{CO}_{2}$ using ellipsometry. ${ }^{19,20}$ They reported that the swelling behavior was different from that of the bulk polymers, and the swelling maximum in PMMA was observed at the pressure where the compressibility of $\mathrm{CO}_{2}$ exhibits a maximum. ${ }^{20}$ However, they were only able to study low pressures up to $12 \mathrm{MPa}$ and were not able to determine the concentration profile of the polymers.
Table 1. Material Characteristics of Polymers Used in This Work

\begin{tabular}{lcccc}
\hline polymer & $\mathrm{M}_{\mathrm{w}}\left(10^{3} \mathrm{~g} / \mathrm{mol}\right)$ & $\mathrm{M}_{\mathrm{w}} / \mathrm{M}_{\mathrm{n}}$ & $\phi_{1,4}(\%)^{\mathrm{a}}$ & $\phi_{\mathrm{ps}}(\%)^{\mathrm{b}}$ \\
\hline d-PB1 & 264 & 1.15 & 80 & \\
d-PB2 & 131 & 1.06 & 80 & \\
d-SBR & 84 & 1.08 & 60 & 47 \\
d-PMMA & 137 & 1.08 & & 100 \\
d-PS & 155 & 1.03 & & 100
\end{tabular}

a Volume fraction of 1,4-linkage in d-PB. ${ }^{b}$ Volume fraction of d-PS component.

The polymers studied vary greatly in their miscibility in the presence of $\mathrm{CO}_{2}$. To explore whether this is a universal phenomena, we compare the swelling characteristics for several classes of polymers, i.e., deuterated PS (d-PS), deuterated polybutadiene (d-PB), and the corresponding random copolymer, deuterated styrenerandom-butadiene copolymer (d-SBR), as well as deuterated PMMA (d-PMMA) in a wide range of $\mathrm{CO}_{2}$ pressures up to $70 \mathrm{MPa}$ under two isothermal conditions $\left(\mathrm{T}=36\right.$ and $50{ }^{\circ} \mathrm{C}$ ). Comparisons between the glassy and rubbery polymers as well as between random copolymers and homopolymers provided us significant insights into the swelling mechanism of polymer thin films in the presence of density fluctuations of $\mathrm{CO}_{2}$.

\section{Experimental Section}

Materials. One of the unique advantages of neutron measurements is that the scattering intensity from a polymer molecule is quite enhanced by using deuterium labeling of the polymer samples. Rubbery polymers were obtained from Polymer Source, and glassy polymers were obtained from Polymer Laboratories. Their molecular characteristics are listed in Table 1. Silicon wafers for NR experiments $(7.5 \mathrm{~cm}$ diameter, $8 \mathrm{~mm}$ thickness) were first placed into a buffered solution with a mixture of $\mathrm{H}_{2} \mathrm{SO}_{4}: \mathrm{H}_{2} \mathrm{O}_{2}=1: 1$ at $\mathrm{T}=100{ }^{\circ} \mathrm{C}$ for $1 \mathrm{~h}$ and rinsed with deionized water. They were then etched by $\mathrm{HF}: \mathrm{H}_{2} \mathrm{O}=3: 7$ solution to remove the native oxide layer. The polymers were dissolved into toluene, and the homoge neous solutions were filtered through a Millipore film of 0.45 $\mu \mathrm{m}$ pore size. The films were spun-cast onto the clean Si substrates with a rotation speed of $2500 \mathrm{rpm}$. The film thickness was measured by an ellipsometer (AutoE 1-II). The as-cast films were then dried in a vacuum oven for $0.5-5 \mathrm{~h}$ at 120-150 ${ }^{\circ} \mathrm{C}$, which depends on the polymers, to relax strains induced in the spinning process. To avoid sample degradation and memory of the pressure history, we used fresh samples for each isothermal set of experiments.

High-Pressure Cell. Figure 2a shows a schematic view of the high-pressure cell for NR experiments. The body of the high-pressure cell was machined from 4340 steel. Sapphire was selected for the optical window material because of high transparency for neutrons (more than 90\%). ${ }^{21}$ F urthermore, sapphire has high tensile strength (elastic limit $448 \mathrm{MPa}$ ), resistance to corrosion, high-energy damage threshold, and low absorbance. Two cylindrical sapphire windows $(2.4 \mathrm{~cm}$ in thick, o.d. $5 \mathrm{~cm}$ ) were installed for transmitting the incident beam and for receiving the reflected beams. The sealing was achieved by a combination of a Teflon and a nylon gasket placed between the sapphire windows. The cell had a volume of about $10 \mathrm{~mL}$ and a maximum pressure rating of $140.0 \mathrm{MPa} . \mathrm{CO}_{2}$ used in this study has a purity of $99.9 \% . \mathrm{CO}_{2}$ was loaded into the cell by means of a hand-operated syringe pump (HIP Equip.) to the desired pressure. Prior to pressurization, the air space is purged with the gas at low pressure. Since only amorphous silicon and fluorinated polymers are " $\mathrm{CO}_{2}$-solubl $\mathrm{e}^{\text {" }}$ at readily accessible conditions $\left(\mathrm{T}<100{ }^{\circ} \mathrm{C}, \mathrm{P}<50 \mathrm{MPa}\right),{ }^{22}$ the successive pressurized and depressurized processes were enabled for NR measurements. Figure $2 b$ shows the general experimental arrangements for $\mathrm{NR}$ experiments. $\mathrm{CO}_{2}$ pressure inside the cell was monitored by using an OMEGADYNE pressure transducer $(\mathrm{TH}-1)$ with a pressure gauge meter 


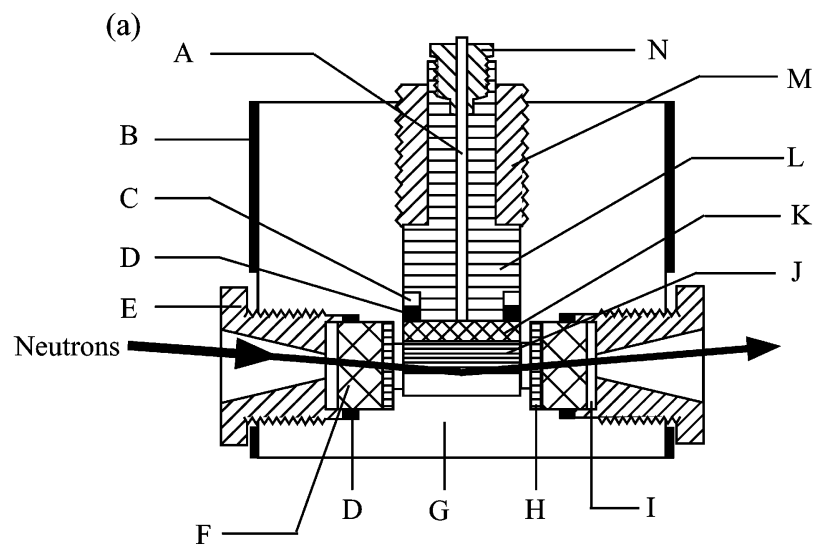

(b)

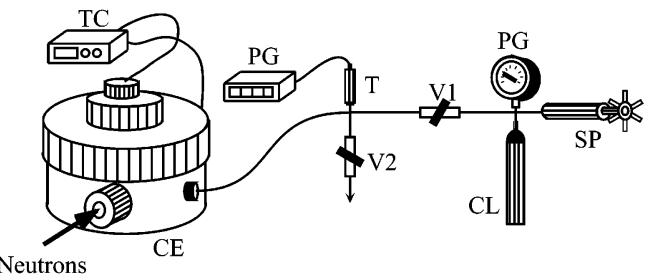

Figure 2. Schematic diagram of (a) high-pressure cell and (b) experimental configuration for NR experiments: (A) thermocouple, (B) heater, (C) backup ring, (D) Teflon O-ring, (E) retainer, $(F)$ sapphire windows, $(G)$ chamber, $(H)$ Teflon gasket (I) nylon gasket, $(\mathrm{J})$ Si wafer (K) Al spacer, (L) cover, (M) main nut, (N) HF4 connection, (CL) $\mathrm{CO}_{2}$ cylinder, (SP) handoperated syringe pump, (PG) pressure gauge, (V1) inlet valve, (V2) release valve, (T) pressure transducer, (TC) temperature controller, (CE) high-pressure chamber.

(I NFS-0001-DC1). The temperature of the cell was controlled by a temperature controller (CAL Controls) equipped with heaters that were installed on the outer side of the cell and a thermocouple (Rama Co.). The temperature of the system was controlled with an accuracy of $\pm 0.1{ }^{\circ} \mathrm{C}$, and the stability of pressure during the measurements was less than $\pm 0.2 \%$.

Neutron Reflectivity. The specular reflectivity measurements were performed at the National Institute of Standards and Technology Center for Neutron Research (NCNR) NG-7 reflectometry. The wavelength of neutrons was $4.7 \AA$ with $\Delta \lambda / \lambda$ $=2 \%$. Because of high absorption of neutrons in compressed $\mathrm{CO}_{2}$, the incident and reflected beams passed through the $\mathrm{Si}$ wafer with a transmission of 0.90 relative to air. Data were obtained both by successively increasing the pressure and then slowly decreasing the pressure under isothermal and isobaric conditions. It should be noted that, as previously described, ${ }^{23}$ the swelling maximum at the ridge in the first pressurized processes was different from those for further cycles due to the pinning of the film onto the Si substrate. In addition to this factor, d-PS thin films showed a hysteresis in the swelling isotherms at low pressures between the pressurized and depressurized cycles due to the glass-liquid transition of the polymers. ${ }^{20,23-27}$ Accordingly, the swelling measurements were conducted in the pressurization process by using pre- $\mathrm{CO}_{2-}$ annealed samples, which were immersed in an $\mathrm{scCO}_{2}$ condition ( $\mathrm{T}=36{ }^{\circ} \mathrm{C}$ and $\mathrm{P}=20.0 \mathrm{MPa}$ ) for $1 \mathrm{~h}$ and were quickly depressurized to atmospheric pressure at constant temperature. We confirmed that the film qualities, such as thickness and roughness, were identical to those of the unswollen thickness before and after the treatment. The equilibrium swelling of the glassy polymer thin films was achieved by 0.5 $\mathrm{h}$ annealing at the desired pressure prior to data collection. The equilibration time for the rubbery polymers in the vicinity of the ridge was much longer ( $\sim 5 \mathrm{~h})$, as will be discussed later.

Since the background scattering from pure $\mathrm{CO}_{2}$ increased dramatically near the critical point, ${ }^{18}$ we monitored the background scattering for each pressure condition as well. The NR data corrected for the background scattering were analyzed by comparing the observed reflectivities with the calculated ones based on model density profiles having three free parameters: film thickness, scattering length density (SLD), and interfacial root-mean-square (rms) roughness $(\sigma)$ between polymer and $\mathrm{CO}_{2}$ layers, which was approximated by an error function. ${ }^{28}$ From the X-ray reflectivity measurements, the thickness of a silicon oxide layer was determined to be $10 \AA$. The thickness was kept constant in all the fitting procedures. The neutron scattering length density (SLD) of $\mathrm{CO}_{2}$ solvent, which is variable from $0.004 \times 10^{-6}$ to $2.75 \times 10^{-6} \AA^{-2}$ in the pressure range of $0.1<\mathrm{P}<70.0 \mathrm{MPa}$ at $\mathrm{T}=36$ and $50{ }^{\circ} \mathrm{C}$, was calculated from the bulk density obtained by the equation of state of $\mathrm{CO}_{2} \cdot{ }^{4}$

\section{Results}

(a) d-PS Thin Films. As we al ready mentioned, the significant advantage of the compressed gases as solvents is that the solvent quality can be easily tuned through temperature and pressure. It is well-known that $\mathrm{CO}_{2}$, by variation of temperature and pressure, can assume the equivalent solvent properties of a range of conventional solvents from pentane to pyridine. The solubility parameters for compressed gases can be calculated from the empirical equation derived by Gidding et al.29

$$
\delta_{1}=1.25 \mathrm{P}_{\mathrm{c}}^{1 / 2}\left[\rho_{\mathrm{r}} / \rho_{\mathrm{r}}(\mathrm{liq})\right]
$$

where $\mathrm{P}_{\mathrm{c}}$ is the critical pressure of the supercritical fluid, $\rho_{r}$ is the reduced density of the fluid, and $\rho_{r}($ liq $)$ is assumed to be 2.66, a typical reduced density of the fluid in the liquid state. The calculated $\delta_{1}$ values by eq 2 range from 0 to approximately $8\left(\mathrm{cal} / \mathrm{cm}^{3}\right)^{1 / 2}$ with increasing pressure at constant temperatures used for the NR measurements. Although the interaction parameter $\chi$ is expressed by two components, i.e., the enthalpic $\left(\chi_{\mathrm{H}}\right)$ and entropic $\left(\chi_{\mathrm{S}}\right)$ components of the thermodynamic interactions, in this instance, we consider only $\chi_{H}$ as a measure of the solvent quality because $\chi_{\mathrm{H}}$ can be easily calculated by the solubility parameters to obtain a qualitative check. $\chi_{H}$ is given as follows:

$$
\chi_{\mathrm{H}} \propto\left(\delta_{1}-\delta_{2}\right)^{2}
$$

where $\delta_{2}$ is the solubility parameter of the polymers, which are $\sim 8.5\left(\mathrm{cal} / \mathrm{cm}^{3}\right)^{1 / 2}$ for the typical polymers, such as PS, PB, and PMMA. ${ }^{30}$ Therefore, the solvent quality of compressed $\mathrm{CO}_{2}$ gas in a polymer is improved as the pressure is increased at constant temperature. Notethat the solubility parameters of the polymers also change as a function of temperature and pressure, but the degree of the change in $\delta_{2}$ is negligible compared with that of $\mathrm{CO}_{2}$.

Figure $3 a$ shows representative NR curves of d-PS thin film at $\mathrm{T}=36^{\circ} \mathrm{C}$. The reflectivity was plotted as a function of the momentum transfer normal to the surface, $\mathrm{q}_{z}=4 \pi \sin \theta / \lambda$, where $\theta$ is the glancing angle of incidence and $\lambda$ is the neutron wavelength, respectively. The solid lines are fit to the single layer density profiles shown in Figure 3b. As shown in the figure, we find that good fits could be obtained with uniform concentration of $\mathrm{CO}_{2}$ in the polymer layer, and no preferential adsorption of either $\mathrm{CO}_{2}$ or polymer occurred at the Si substrate surface. The thickness of the layer, which was initially $445 \AA$ thick, increased to 513 $\AA$ at $\mathrm{P}=8.2 \mathrm{MPa}$ and then decreased again to $483 \AA$ upon compression up to $\mathrm{P}=20.6 \mathrm{MPa}$. The interfacial root-mean-square (rms) roughness $(\sigma)$ between the polymer and $\mathrm{CO}_{2}$ layers, which was initially $10 \AA$ at 

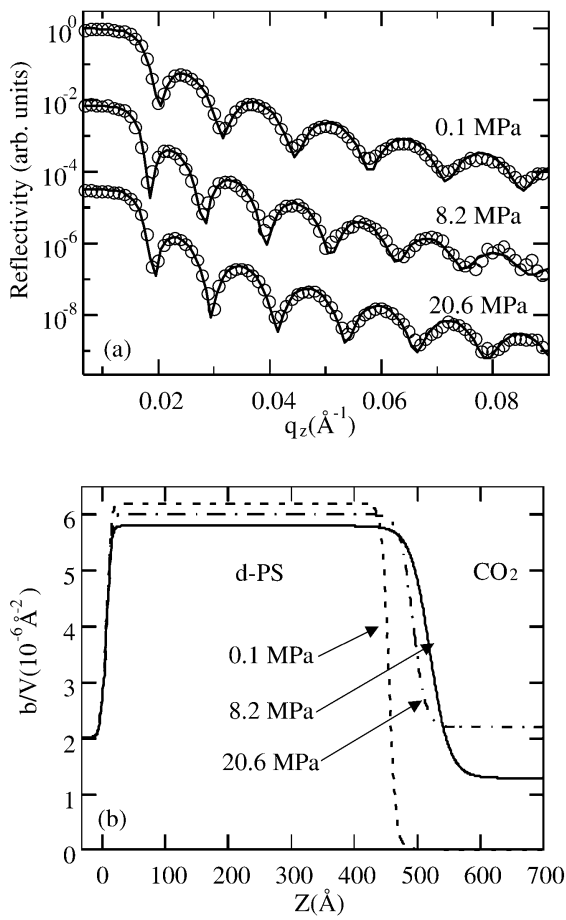

Figure 3. (a) Representative reflectivity data for d-PS at T= $36{ }^{\circ} \mathrm{C}$. Consecutive reflectivities have been offset from each other for clarity. Solid lines represent the reflectivity calculated from corresponding concentration profiles shown in (b): solid line, $\mathrm{P}=0.1 \mathrm{MPa}$; dotted lines, $\mathrm{P}=8.2 \mathrm{MPa}$; solid-dotted lines, $\mathrm{P}=20.6 \mathrm{MPa}$

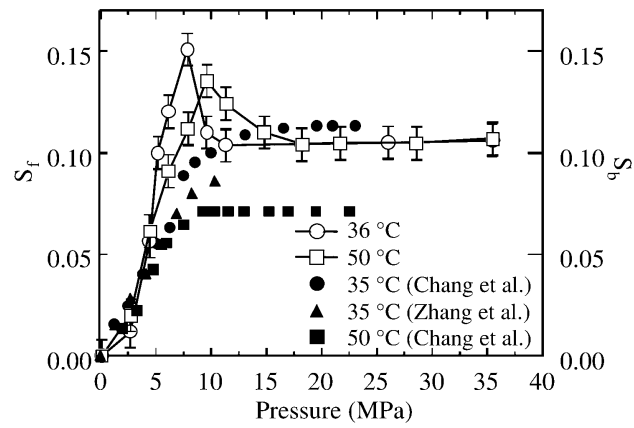

Figure 4. Comparison of swelling isotherms between d-PS thin film and bulk in $\mathrm{CO}_{2}$. Bulk data are from refs 8 and 9.

atmospheric pressure, increased to $28 \AA$ at $\mathrm{P}=8.2 \mathrm{MPa}$ and then decreased again to $18 \AA$ at $\mathrm{P}=20.6 \mathrm{MPa}$. It should be noted that the roughness after the complete depressurization to atmospheric pressure decreased to about $10 \AA$, indicating that large voids such as those reported in bulk PS films do not occur. 31,32 This is further confirmed by an atomic force microscopy (AFM) scan of the surface topography from d-PS thin film exposed to several cycles of in beam pressurizing and depressurizing, where the surface appears flat with the same rms roughness of $\sim 10 \AA$ as that obtained from the NR results. ${ }^{23}$

In Figure 4 we plot the linear dilation $\left(\mathrm{S}_{f}\right)$ of the d-PS films at $\mathrm{T}=36$ and $50{ }^{\circ} \mathrm{C}$. The linear dilation was calculated from the equation $S_{f}=\left(L-L_{0}\right) / L_{0}$, where $L$ and $L_{0}$ are the measured thickness of the swollen and unswollen polymer thin films, respectively. The maximal $\mathrm{S}_{\mathrm{f}}$ values were 0.15 at $\mathrm{T}=36^{\circ} \mathrm{C}$ and $\mathrm{P}=8.2 \mathrm{MPa}$ and 0.13 at $\mathrm{T}=50{ }^{\circ} \mathrm{C}$ and $\mathrm{P}=10 \mathrm{MPa}$, which occur along the density fluctuation ridge. Similar swelling behavior was previously reported for a different molecular weight d-PS $\left(\mathrm{M}_{\mathrm{w}}=957 \times 10^{3}\right)$ with the same film
Table 2. Characteristic Parameters of Polymers To Obtain $\chi$-Parameters

\begin{tabular}{lrccc}
\hline polymers & $\mathrm{R}_{\mathrm{g}}(\AA)^{\mathrm{a}}$ & $\mathrm{a}(\AA)^{\mathrm{b}}$ & $\mathrm{L}_{0}(\AA)$ & $\mathrm{L}_{0} / \mathrm{R}_{\mathrm{g}}$ \\
\hline d-PB1 & 145 & 5.8 & 615 & 4.3 \\
d-SBR & 83 & $6.3^{\mathrm{c}}$ & 370 & 4.5 \\
d-PS & 103 & 6.7 & 445 & 4.3 \\
d-PMMA & 98 & 6.5 & 450 & 4.6
\end{tabular}

${ }^{a} R_{g}=\sqrt{N / 6} a$. ${ }^{b}$ Segment lengths (obtained from ref 50 ). ${ }^{c} a_{s b r}{ }^{2}=\phi_{p s} a_{p s}{ }^{2}+\left(1-\phi_{p s}\right) a_{p b}{ }^{2}$ with volume fraction of d-PS $\left(\phi_{p s}\right)$.

thickness in $\mathrm{CO}_{2} \cdot{ }^{23} \mathrm{H}$ owever, the maxima of the higher $\mathrm{M}_{\mathrm{w}}$ d-PS thin films at the ridge were much larger $\left(\mathrm{S}_{\mathrm{f}}=\right.$ 0.25 at $\mathrm{T}=36{ }^{\circ} \mathrm{C}$ and $\mathrm{P}=8.2 \mathrm{MPa}$ and $\mathrm{S}_{\mathrm{f}}=0.22$ for $\mathrm{T}$ $=50^{\circ} \mathrm{C}$ and $\mathrm{P}=10.0 \mathrm{MPa}$ ) than those shown in Figure 4. This is due to the fact that the anomalous swelling is scaled with the polymer radius of gyration $\left(R_{g}\right) .{ }^{18}$ In the case of higher $M_{w}$ d-PS thin films, the value of $L_{0} / R_{g}$ corresponds to 1.7 while that used in the present study is 4.3 (see Table 2). At further compression up to $P=$ $35.0 \mathrm{MPa}, \mathrm{S}_{\mathrm{f}}$ decreased to a constant value of approximately 0.1 for both temperature conditions. Chang et al.$^{9}$ measured the swelling of bulk PS by using a cathetometer in the pressure range up to $25 \mathrm{MPa}$ at T $=35$ and $50{ }^{\circ} \mathrm{C}$ (Figure 4). To compare the swelling between the thin and bulk films, we assumed that the swelling of the thin films was uniaxial $19,20,33,34$ while that of the bulk $\left(S_{b}\right)$ was isotropic, i.e., $S_{b}=\left(\left(L-L_{0}\right) / L_{0}\right)^{3}$. From the figure we can see that the rate of swelling in the bulk is maximal near the critical pressure, and a plateau, with no minima, in the swelling at a value of about 0.1 occurs, which follows closely the increase in density of $\mathrm{CO}_{2}$ with pressure, i.e., density-dependent enhancement in solvent quality. Consequently, except for the excess swelling region, the swelling behavior of d-PS thin films at $\mathrm{T}=36^{\circ} \mathrm{C}$ was in good agreement with that in the bulk. On the other hand, the swelling of the d-PS thin film at T $=50{ }^{\circ} \mathrm{C}$ exceeded $30 \%$ that of the bulk in the supercritical region. Similar deviation has been observed in PDMS thin film- $\mathrm{CO}_{2}$ mixtures below $\mathrm{P}_{\mathrm{c} .}{ }^{19}$ Some explanations concerning this deviation, such as the enhanced adsorption of $\mathrm{CO}_{2}$ on the polymer thin film and polymer/ $\mathrm{CO}_{2}$ interface or a change in polymer chain conformation near a solid surface related to the bulk, were pointed out. Further studies are currently in progress.

(b) d-PB Thin Films. The similar swelling maxima were induced at the density fluctuation ridge in not only d-SBR $\left(S_{f}=0.6\right)^{18}$ but also d-PS thin films. However, the maximal values were completely different between them even under the same scaled thickness $\left(L_{0} / R_{g} \sim\right.$ 4.5). To determine the effect of a random copolymer on the anomal ous swelling, we examined d-PB thin films, which also have poor miscibility with $\mathrm{CO}_{2}$ in the bulk. Note that the unswollen film thickness of $615 \AA$, which corresponds to $L_{0} / R_{g}=4.3$ (see Table 2), was prepared to compare the swelling quantitatively. In Figure $5 a S_{f}$ for d-PB1 thin film at $\mathrm{T}=36{ }^{\circ} \mathrm{C}$ as a function of pressure is plotted. Compared with the swelling isotherm for $\mathrm{d}$-SBR thin films, ${ }^{18}$ the swelling behavior including the anomalous peak at the ridge is almost identical to that of d-SBR thin films. We can therefore conclude that the difference in the swelling at the ridge is not due to random copolymer composition but mainly the elasticity of the polymers.

Next, we focus on the $R_{g}$ dependence of the swelling behavior for d-PB thin films. As we have already clarified, the anomalous swelling in d-PS thin films was 

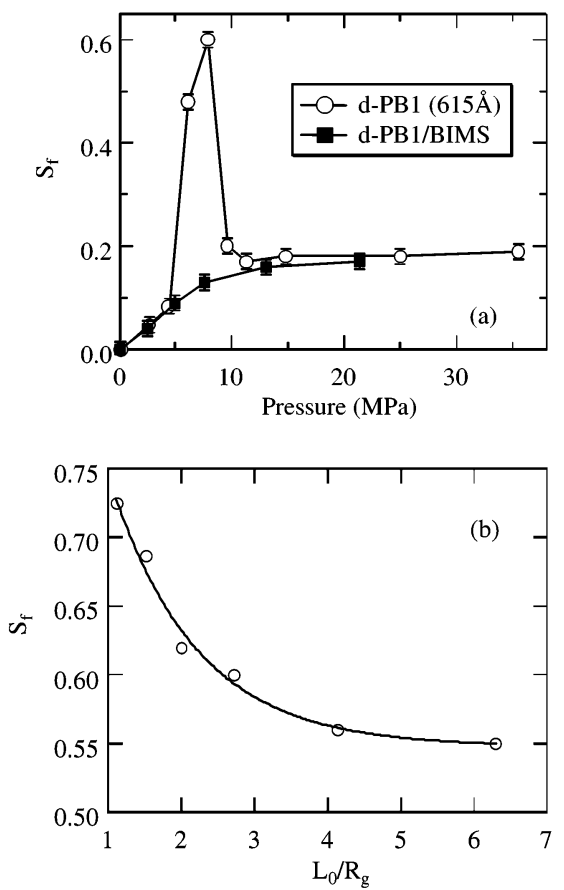

Figure 5. (a) Pressure dependence of $S_{f}$ for d-PB1 (open circles) and d-PB1/BIMS (filled squares) at $T=36{ }^{\circ} \mathrm{C}$. (b) Excess swelling as a function of scaled thickness for d-PB. The solid line shows the best-fit result of the measured swelling with the exponential function (eq 4).

Table 3. Swelling Maxima in d-PB $-\mathrm{CO}_{2}$ Mixtures at $\mathbf{T}=$ $36{ }^{\circ} \mathrm{C}$ and $\mathrm{P}=8.2 \mathrm{MPa}$

\begin{tabular}{cccc}
\hline polymer & $\mathrm{L}_{0}(\AA)$ & $\mathrm{L}_{0} / \mathrm{R}_{\mathrm{g}}(\AA)$ & $\mathrm{S}_{\mathrm{f}}$ \\
\hline d-PB1 & 176 & 1.1 & 0.73 \\
d-PB1 & 315 & 2.0 & 0.62 \\
d-PB1 & 615 & 4.3 & 0.56 \\
d-PB1 & 993 & 6.3 & 0.54 \\
d-PB2 & 169 & 1.5 & 0.68 \\
d-PB2 & 307 & 2.7 & 0.60
\end{tabular}

scaled by $R_{g}$ and was a surface effect which occurs only within $\sim 10 \mathrm{R}_{\mathrm{g}}$ thickness of the d-PS/CO $\mathrm{CO}_{2}$ interface. ${ }^{18}$ To explore whether the scaling behavior is a universal phenomena in thin films, we measured the $\mathrm{R}_{\mathrm{g}}$ dependence of the swelling for the d-PB thin films. In Figure $5 b$ we plot $S_{f}$ for the d-PB thin films with varying thickness from 169 to $993 \AA$ using two different $M_{w}$ of d-PB at $\mathrm{T}=36{ }^{\circ} \mathrm{C}$ and $\mathrm{P}=8.2 \mathrm{MPa}$. The details are summarized in Table 3. From the figure, it is clear that as the scaled film thickness is increased, the $S_{f}$ values at the ridge decrease. The $S_{f}$ value reached 0.73 at $L_{0} /$ $R_{g}=1.1$. Especially, the $S_{f}$ values drastically changed when the thickness was less than $3 R_{g}$ and was in agreement with the exponential function shown by the solid line, i.e.,

$$
\begin{aligned}
\mathrm{S}_{\mathrm{f}}\left(\mathrm{T}=36{ }^{\circ} \mathrm{C}, \mathrm{P}=\right. & 8.2 \mathrm{MPa})= \\
& 0.55+0.46 \exp \left[-0.85 \mathrm{~L}_{\mathrm{o}} / \mathrm{R}_{\mathrm{g}}\right]
\end{aligned}
$$

Similar exponential behavior of linear dilation was observed in d-PS thin films in $\mathrm{CO}_{2} \cdot{ }^{18}$ However, two major differences can be pointed out: (i) the constant in the exponential function for $\mathrm{d}$-PB is much larger than that for d-PS (0.44), indicating that the $S_{f}$ values for d-PB change more drastically as a function of $L_{0} / R_{g}$, and (ii) the markedly larger $S_{f}$ value $(\sim 0.55)$ at $L_{0} / R_{g} \sim 7$ for d-PB while that of d-PS is close to the bulk value. In this case the bulk swelling was simulated by using

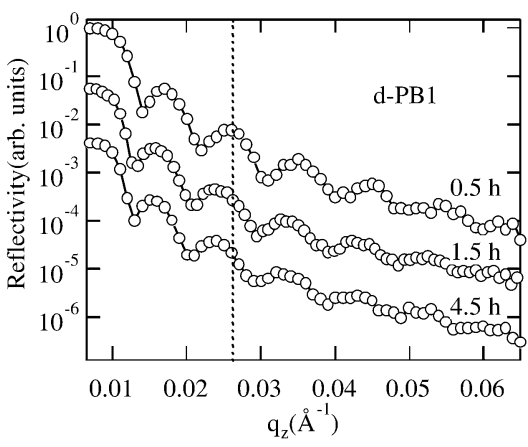

Figure 6. Time dependence of $\mathrm{NR}$ curves for d-PB-CO mixture at $\mathrm{T}=36{ }^{\circ} \mathrm{C}$ and $\mathrm{P}=8.2 \mathrm{MPa}$.

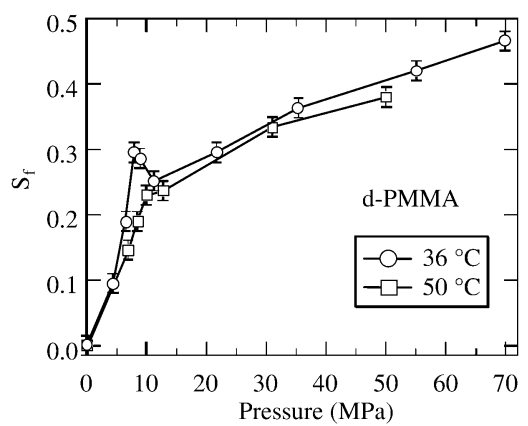

Figure 7. Linear dilation of d-PMMA as a function of pressure at $\mathrm{T}=36^{\circ} \mathrm{C}$ and $50^{\circ} \mathrm{C}$.

the bilayer of brominated poly(isobutylene-co-p-methylstyrene) (BIMS) and d-PB, in which a $1 \mathrm{~mm}$ thick disk of BIMS was directly pressed onto the d-PB layer. The BIMS Iayer was not deuterated and served as a "cap" for the bottom d-PB film. If the penetration of density fluctuations is accessible down to the d-PB film, it is expected that a similar swelling peak at the ridge in the bilayer systems would be observed. As shown in Figure 5a, however, the NR measurements showed approximately an $8 \%$ swelling with no maxima at the ridge, indicating that the anomal ous swelling in d-PB thin films disappeared in the bulk. Consequently, the polymer chains of d-PB films hold the high-stretching configurations even up to larger film thickness in the presence of large density fluctuations in $\mathrm{CO}_{2}$. This insensitivity to the film thickness for $\mathrm{d}-\mathrm{PB}$ thin films is analogous to that for PMMA films, which showed that the anomal ous swelling existed even to $3210 \AA$, which is equivalent to the thickness of more than $25 \mathrm{R}_{\mathrm{g}} \cdot{ }^{20}$

At this point, it is important to detail the kinetics of the swelling at the ridge. Figure 6 shows the time dependence of the NR curves for the d-PBI thin film $\left(\mathrm{L}_{0}=615 \AA\right)$ at $\mathrm{T}=36^{\circ} \mathrm{C}$ and $\mathrm{P}=8.2 \mathrm{MPa}$. From the figure, a $0.5 \mathrm{~h}$ annealing procedure, which is enough to reach the equilibrium swelling state for the glassy polymers including the ridge condition as well as the d-PB polymers except for the ridge condition, was not sufficient for $\mathrm{d}$-PB films at the ridge. It was found that $4.5 \mathrm{~h}$ annealing was required to obtain the equilibrium swelling at the ridge. The change of the frequency in NR curves from 0.5 to $4.5 \mathrm{~h}$ annealing corresponds to a $30 \AA$ increase in thickness. It should be noted that the d-SBR films also showed similar slow dynamics at the ridge, irrespective of the chain composition, indicating that the slow dynamics is mainly due to the high viscosity of the rubbery polymers.

(c) d-PMMA Thin Films. Figure 7 shows the pressure dependence of linear dilation for d-PMMA thin 
films at $\mathrm{T}=36$ and $50^{\circ} \mathrm{C}$. From the figure we can see the similar anomalous peaks at the ridge, which are intermediate values between d-PS and d-PB under the same temperature and pressure conditions. Sirard et al. observed the similar swelling maxima in hydrogenated PMMA- $\mathrm{CO}_{2}$ mixtures, ${ }^{20}$ suggesting that the anomaly in the swelling behavior is independent of the deuteration of the polymers. As they pointed out, the anomalous swelling does not occur in the swelling of bulk PMMA. ${ }^{7,8} \mathrm{~A}$ further interesting point is the swelling behavior in the higher pressure range between 20 $<\mathrm{P}<70 \mathrm{MPa}$, which is far beyond their accessible pressure range; $\mathrm{S}_{f}$ increased with increasing pressure to 0.45 while those of the d-PS, d-PB, and d-SBR thin films collapsed to the constant $S_{f}$ values of $0.1-0.2$. This indicates that the solvent quality of $\mathrm{CO}_{2}$ in d-PMMA is much better than those in the other polymers at high pressure where the effect of density fluctuations can be ignored. ${ }^{18}$ It is well-known that the better miscibility between $\mathrm{CO}_{2}$ and PMMA is due to the specific intermolecular interaction between the PMMA carbonyl oxygen and the carbon atom of $\mathrm{CO}_{2} \cdot{ }^{35}$ Hence, it is obvious that when processed as thin films, the sol ubility of $\mathrm{CO}_{2}$ near the critical point is significantly enhanced by large density fluctuations in $\mathrm{CO}_{2}$. It should be added that the $\mathrm{S}_{f}$ values of d-PMMA films at high pressures tend to decrease with increasing temperature, since the solubility depends on the $\mathrm{CO}_{2}$ density as seen in the bulk. ${ }^{7,8}$

\section{Discussion}

There are two types of density inhomogeneities in SCFs with different length scales:2,36 (a) long-range density inhomogeneities, which are referred to as "indirect density inhomogeneities" because of their indirect dependence on the solute-solvent interaction, i.e., solvent-solvent density correlations present in the compressible region; (b) short-range density inhomogeneities, so-called "direct density inhomogeneities", which are arise from the direct solute-solvent correl ation. 37,38 Although the short-range density inhomogeneities are al so influenced by the proximity of the solvent's critical point, they do not show the criticality, as seen in the long-range density inhomogeneities. It is well-known that the long-range density fluctuations influence the rate of increase in solubility with respect to temperature and pressure while the short-range ones control the absolute solubility. In contrast, the present study clearly proved that the long-range density inhomogeneities directly control the absolute solubility of $\mathrm{CO}_{2}$ in the polymer thin films as a function of the magnitude of density fluctuations in $\mathrm{CO}_{2}$. In addition, the comparison between the linear dilation and density fluctuation isotherms leads to an important conclusion: the anomalous swelling, which corresponds to the regions of 4.5 $<\mathrm{P}<11.3 \mathrm{MPa}$ at $\mathrm{T}=36{ }^{\circ} \mathrm{C}$ and $4.5<\mathrm{P}<14.7 \mathrm{MPa}$ at $\mathrm{T}=50^{\circ} \mathrm{C}$ (see Figure 4), is induced with the condition of $\left\langle(\Delta N)^{2}\right\rangle /\langle N\rangle \geq 1.6$ for all the polymer thin films used in this study. Note that $\left\langle(\Delta N)^{2}\right\rangle\langle\langle N\rangle$ of 1 corresponds to that for the ideal gas state.

Next, we shall discuss the interaction parameter between $\mathrm{CO}_{2}$ and polymers. Supercritical gas-polymer systems present special problems in order to express their $\mathrm{P}-\mathrm{V}-\mathrm{T}$ properties since the two components are quite dissimilar. Polymer solution theory, such as the Flory-Huggins model, does not consider the volume change on the mixing so that it may not be an accurate model for polymer $-\mathrm{CO}_{2}$ mixtures. ${ }^{39}$ The lattice models, such as the Sanchez-Lacombe (S-L) equation of state or the Panayi otou-Vera equation of state models, have been used successfully to describe the thermodynamics of bulk polymer-supercritical mixtures. ${ }^{7,8,14-16}$ I ndeed, Zhang et al. ${ }^{8}$ clarified that the bulk PS swelling behavior at $\mathrm{T}=35^{\circ} \mathrm{C}$ and in the range between $0<\mathrm{P}<11 \mathrm{MPa}$ (see Figure 4) could be modeled accurately using the $\mathrm{S}-\mathrm{L}$ equation of state. This indicates, however, that the $S-L$ equation of state cannot describe the anomal ous swelling in thin films near the ridge because the single adjustable parameter for polymer- $\mathrm{CO}_{2}$ interactions in the $\mathrm{S}-\mathrm{L}$ equation of state is constant at a fixed temperature. As Garg et al. pointed out, 14 there are still uncertainties in these equations of state models even in the bulk polymer- $\mathrm{CO}_{2}$ mixtures because of the relatively poor thermodynamic modeling of $\mathrm{CO}_{2} \mathrm{com}$ pared to that of the polymers.

To describe the phase equilibria of binary mixtures, Shim and J ohnston ${ }^{12}$ and Chang et al..$^{9}$ calculated the fugacity of $\mathrm{CO}_{2}$ in both the polymers and fluid phase given by Prausnitz et al. ${ }^{40}$ Combined with the Flory theory, ${ }^{41}$ they could successfully express the swelling behavior of silicon rubber, PS, and poly(ethylene terephthalate) (PET) in $\mathrm{CO}_{2}$. As mentioned above, the Flory theory is not ideal in expressing the thermodynamics of the polymers; however, as expressed in eq 5, it could be more convenient to use the volume fraction of $\mathrm{CO}_{2}$ for expressing the combined effect of temperature and pressure on the interaction parameter.

According to the Flory theory for the fluid-polymer systems, the relation between $\chi$ and vol ume fraction of the polymer in the mixture, $\phi_{p}$, is expressed as follows:

$$
\begin{aligned}
\ln (\alpha)=\left(\mu_{1}-\mu_{0}\right) / R T & = \\
& \ln \left(1-\phi_{\mathrm{p}}\right)+(1-1 / \mathrm{x}) \phi_{\mathrm{p}}+\chi \phi_{\mathrm{p}}{ }^{2}
\end{aligned}
$$

where $\alpha$ is the activity of the $\mathrm{CO}_{2}$ in the polymer that is related to the chemical potential, $\mu_{1}$ is the chemical potential of the solvent in the solution, $\mu_{0}$ is the chemical potential in the pure liquid, and $x$ is the ratio of the molar volumes of the polymer to solvent. The activity of $\mathrm{CO}_{2}$ can be approximately expressed as $\alpha=\mathrm{P}_{1} / \mathrm{P}_{1}^{0}$ assuming the absence of the strong polymer- $-\mathrm{CO}_{2}$ interactions. However, Fleming and Koros pointed out that the approximation of the activity was not valid near the critical point. ${ }^{11}$ Therefore, we used the equation derived by Prausnitz et al. ${ }^{40}$ to express the activity of $\mathrm{CO}_{2}$

$$
\alpha=\frac{\sigma \mathrm{P}}{\mathrm{P}^{\text {sat }} \sigma^{\text {sat }} \exp \left(\frac{\mathrm{v}^{\mathrm{p}}\left(\mathrm{P}-\mathrm{P}^{\mathrm{sat}}\right)}{\mathrm{RT}}\right)}
$$

where $\sigma$ is the fugacity coefficient, $\mathrm{P}$ sat is the hypothetical vapor pressure, $\sigma^{\text {sat }}$ is the fugacity coefficient at the vapor pressure, and $\mathrm{v}^{\mathrm{p}}\left(=46 \mathrm{~cm}^{3} / \mathrm{mol}\right)$ is the molar volume of $\mathrm{CO}_{2}$ in the polymer phase. ${ }^{11}$ The value of $\mathrm{P}$ sat in the polymer phase at $\mathrm{T}=36^{\circ} \mathrm{C}$ was determined from the log-linear extrapolation of the vapor pressure curve of $\mathrm{CO}_{2}{ }^{11}$ The fugacity coefficient of $\mathrm{CO}_{2}$, which describes nonideality of the fluid phase, was obtained from the Peng-Robinson equation of state. ${ }^{42}$ To compare the interaction parameters for all the polymers used, the solubility data in the pressure range of $4.5<\mathrm{P}<35.0$ $\mathrm{MPa}$ were chosen since the glassy polymers were adopted as the rubber state in the pressure range based on interdiffusion experiments by using NR. ${ }^{24}$ 


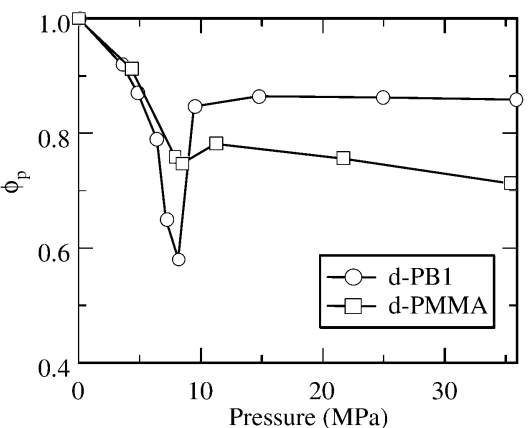

Figure 8. Pressure dependence of $\phi_{\mathrm{p}}$ for d-PB 1 (circles) and d-PMMA (squares) at $\mathrm{T}=36^{\circ} \mathrm{C}$.

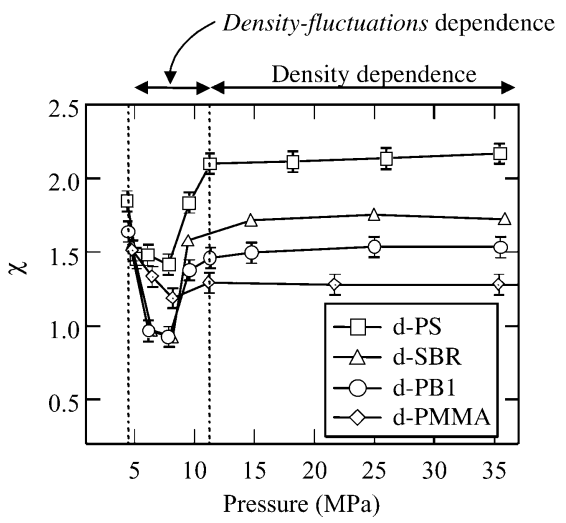

Figure 9. Pressure dependence of $\chi$ parameters between $\mathrm{CO}_{2}$ and the polymers at $\mathrm{T}=36^{\circ} \mathrm{C}$.

The $\phi_{\mathrm{p}}$ values were directly calculated from the scattering length density (SLD) parameters from NR curves, which are proportional to the density of the films. Assuming that the concentration of the mixture components are homogeneous through the entire film, SLD of the polymer- $\mathrm{CO}_{2}$ mixture, $S L D_{\text {mix }}$, can be expressed as a linear combination of SLD for the polymer, SLD , and SLD for $\mathrm{CO}_{2}, \mathrm{SLD}_{\mathrm{co}}$

$$
\operatorname{SLD}_{\text {mix }}=\operatorname{SLD}_{\mathrm{p}} \phi_{\mathrm{p}}+\operatorname{SLD}_{\mathrm{co}}\left(1-\phi_{\mathrm{p}}\right)
$$

The density of $\mathrm{CO}_{2}$ dissol ved in the polymers was taken to be $0.956 \mathrm{~g} / \mathrm{cm}^{3} .{ }^{43}$ From the best-fit results between the observed and model density profiles, we determined the $\phi_{\mathrm{p}}$ values as a function of pressure and temperature, as shown in Figure 8.

Figure 9 shows pressure dependence of the $\chi$-parameters for d-PS, d-PB, d-SBR, and d-PMMA films at T = $36{ }^{\circ} \mathrm{C}$ calculated by eq 5 . It should be noted that since the solubility of $\mathrm{CO}_{2}$ strongly depends on the scaled thickness, we fixed the $L_{0} / R_{g}$ values to $\sim 4.3$ to discuss the interaction parameter quantitatively (see Table 2). In the anomal ous region of $4.5<\mathrm{P}<11.3 \mathrm{MPa}$ in which the excess swelling occurred, the $\chi$-parameters decreased approaching the ridge and then increased dramatically after crossing the ridge, indicating that the $\chi$-parameters follow the magnitude of the density fluctuations in $\mathrm{CO}_{2}{ }^{18} \chi$-parameters of d-SBR and d-PB in the region were much smaller than that of d-PMMA, which show a better miscibility at high pressures, and were identical irrespective of d-PS components ( $50 \%)$ in d-SBR films. We can therefore conclude that the enhanced solubility of $\mathrm{CO}_{2}$ in the polymers is a function of the elasticity of the polymer rather than the solubility parameter near the density fluctuation ridge. In the deep supercritical region, $\chi$-parameters for all the polymers saturated to constant values and the solvent quality of $\mathrm{CO}_{2}$ show bulk behavior among d-PS, d-PB, and d-SBR, i.e., d-PB > d-SBR > d-PS. Hence, we can see the transition in the solubility of $\mathrm{CO}_{2}$ from the density fluctuations-dependent regi on near the ridge to the density-dependent region at $\mathrm{P}>11.3 \mathrm{MPa}$, where the effect of the density fluctuations can be ignored and the solvent quality is approximately expressed by eq 2 . Furthermore, the $\chi$-parameters for d-PB and d-SBR thin films were estimated to be 0.93 at the ridge. Surprisingly, these values are found to be almost identical to $\chi$-parameter for the silicone rubber, which shows a high $\mathrm{CO}_{2}$ solubility under the isothermal condition at $\mathrm{T}=$ $35{ }^{\circ} \mathrm{C}(0<\mathrm{P}<35 \mathrm{MPa}) .{ }^{12}$ Thus, the large density fluctuations of $\mathrm{CO}_{2}$ enhance the solvent quality to nearly good condition for the immiscible rubber thin films. Currently, we are quantitatively studying the solvent quality of $\mathrm{CO}_{2}$ near the density fluctuation ridge using the chemically end-grafted polymer brush. Karim et al. ${ }^{44}$ showed that the observed end-grafted PS brush profiles were in good agreement with those predicted by selfconsistent-field theory ${ }^{45,46}$ and Monte Carlo and molecular dynamics calculations $s^{47,48}$ as a function of the solvent quality. Details will be described elsewhere. ${ }^{49}$

\section{Conclusions}

We have performed in situ neutron reflectivity measurements to investigate the thermodynamics of the swollen polymer thin films in the presence of $\mathrm{CO}_{2}$. Large density fluctuations of $\mathrm{CO}_{2}$ near the density fluctuation ridge were found to drastically enhance the swelling and solubility for all the polymers examined. The effect was more pronounced in the rubbery polymers than in the glassy polymers so that the anomal ous swelling cannot be explained by the concept of the bulk solubility parameters. The excess swelling showed the film thickness dependence scaled with $R_{g}$, especially, when the film thicknesses were less than $3 R_{g}$, where the effect was more pronounced. The enhanced miscibility between the rubbery polymer thin films and $\mathrm{CO}_{2}$, which show typical poor bulk miscibility, is close to that of silicon rubber $-\mathrm{CO}_{2}$ mixture, which is one of the miscible polymers under the moderate $\mathrm{CO}_{2}$ condition. We believe that the increased miscibility associated with high compressibility of the solvent is not specific to either the compressed gas or the polymer system. In situ NR experiments with the different compressed gases, such as pentane or ethane, are currently in progress.

Acknowledgment. We are grateful to Dr. J ohn Fulton at Pacific Northwest Laboratory for helpful discussions about the high-pressure cell. Support of this work by the NSF-MRSEC (DMR-9632525) is gratefully acknowledged.

\section{References and Notes}

(1) McHugh, M. A.; Krukonis, V. Supercritical Fluids Extraction Principles and Practice; Woburn, MA, 1994.

(2) Tucker, S. C. Chem. Rev. 1999, 99, 391.

(3) Stanley, H. E. Introduction to PhaseTransition and Critical Phenomena; Oxford University Press: Oxford, 1971.

(4) Huang, F. H.; Li, M. H.; Starling, K. E.; Chung, F. T. H. J . Chem. Eng. J pn. 1985, 18, 490.

(5) Nishikawa, K.; Tanaka, I.; Amemiya, Y.J . Phys. Chem. 1996, $100,418$.

(6) Nishikawa, K.; Morita, T. Chem. Phys. Lett. 2000, 316, 238.

(7) Wissinger, R. G.; Paulaitis, M. E. J . Polym. Sci., Polym. Phys. Ed. 1987, 25, 2497. 
(8) Zhang, Y.; Gangwani, K. K.; Lemert, R. M. J . Supercrit. Fluids 1997, 11, 115

(9) Chang, S. H.; Park, S. C.; Shim, J .J J . Supercrit. Fluids 1998 $13,113$.

(10) Goel, S. K.; Beckman, E. J . Polymer 1993, 34, 1410

(11) Fleming, G. K.; Koros, W. J . Macromolecules 1986, 19, 2285.

(12) Shim, J. J .; J ohnston, K. P. AlChE J . 1989, 35, 1097.

(13) Briscoe, B. J .; Zakaria, S. J . Polym. Sci., Part B 1991, 29, 989.

(14) Garg, A.; Gulari, E.; Manke, W. Macromolecules 1994, 27, 5643.

(15) Royer, J . R.; DeSimone, J . M.; Khan, S. A. Macromolecules 1999, 32, 8965.

(16) Kiszka, M. B.; Meilchen, M. A.; McHugh, M. A. J . Appl. Polym. Sci. 1988, 36, 583

(17) Sanchez, I. C. Physics of Polymer Surface and Interface Butterworth-Heinemann: Boston, 1992.

(18) Koga, T.; Seo, Y.-S.; Zhang, Y.; Shin, K.; Kusano, K.; Nishikawa, K.; Rafailovich, M. H.; Sokolov, J . C.; Chu, B.; Peiffer, D. G.; Satija, S. K. Phys. Rev. Lett. 2002, 89, 125506.

(19) Sirard, S. M.; Green, P. F.; J ohnston, K. P. J . Phys. Chem. B 2001, 105, 766

(20) Sirard, S. M.; Ziegler K. J .; Sanchez, I. C.; Green, P. F.; J ohnston, K. P. Macromol ecules 2002, 35, 1928. Although the anomalous swelling maxima have been reported, the relationship between the swelling maxima and the density fluctuation ridge was never mentioned in this work.

(21) McClain, J . B.; Londono, D.; Combes, J . R.; Romack, T. J .; Canelas, D. A.; Betts, D. E.; Wignall, G. D.; Samulski, E. T.; DeSimone, J. M. J . Am. Chem. Soc. 1996, 118, 917.

(22) Kendall, J . L.; Canelas, D. A.; Young, J . L.; DeSimone, J . M. Chem. Rev. 1999, 99, 543.

(23) Koga, T.; Shin, K.; Zhang, Y.; Seo, Y.-S.; Rafailovich, M. H.; Sokolov, J . C.; Chu, B.; Satija, S. K. J . Phys. Soc. J pn., Suppl. A 2001, 347

(24) Koga, T.; Seo, Y.-S.; Hu, X.; Kwanwoo, S.; Zhang, Y.; Rafailovich, M. H.; Sokolov, j. C.; Chu, B.; Satija, S. K. Europhys. Lett. 2002, 60, 559.

(25) Wang, W. V.; Kramer, E. J .; Sachse, W. H. J . Polym. Sci., Polym. Phys. Ed. 1982, 20, 1371.

(26) Condo, P. D.; Sanchez, I. C.; Panayiotou, C. G.; J ohnston, K. P. Macromolecules 1992, 25, 6119.

(27) Condo, P. D.; Paul, D. R.; J ohnston, K. P. Macromolecules 1994, 27, 365
(28) Russell, T. P. Mater. Sci. Rep. 1990, 5, 171

(29) Giddings, J . C.; Myers, M. N.; McLaren, L.; Keller, R. A. Science 1968, 162, 67.

(30) Polymer Handbook, 4th ed.; Brandrup, J ., Immergut, E. H., Eds.; J ohn Wiley \& Sons: New York, 1999.

(31) Arora, K. A.; Lesser, A. J .; McCarthy, T. J . Macromolecules 1998, 31, 4614.

(32) Stafford, C. M.; Russell, T. P.; McCarthy, T. J . Macromolecules 1999, 32, 7610

(33) Stamatialis, D. F.; Wessling, M.; Sanopoulou, M.; Strathmann, H.; Petropoulos, J. H. J. Membr. Sci. 1997, 130, 75

(34) Sefcik, M. D. J . Polym. Sci., Part B: Polym. Phys. 1986, 24, 935.

(35) Kazarian, S. G.; Vincent, M. F.; Bright, F. V.; Liotta, C. L.; Eckert, C. A. J . Am. Chem. Soc. 1996, 118, 1729.

(36) Eckert, C. A.; Kuntson, B. L; Debenedetti, P. G. Nature (London) 1996, 383, 313.

(37) Chialvo, A. A.; Cummings, P. T. AlChE J . 1994, 40, 1558.

(38) Carlier, C.; Randol ph, T. W. AIChE J . 1993, 39, 876.

(39) Maloney, D. P.; Prausnitz, J . M. Ind. Eng. Chem. Process Des. Dev. 1976, 15, 216

(40) Prausnitz, J . M.; Lichtenthaler, R. N.; de Azevedo, E. G. Molecular Thermodynamics of Fluid-Phase Equilibria; Prentice-Hall: Englewood Cliffs, NJ , 1986; Chapter. 7.

(41) Flory, P. J . Principle of Polymer Chemistry; Cornell University Press: Ithaca, NY, 1969.

(42) Peng, D. Y.; Robinson, D. B. Ind. Eng. Chem. Fundam. 1976 15, 59.

(43) Fleming, G. K.; Koros, W. J . J . Polym. Sci., Part B: Polym. Phys. 1987, 25, 2033.

(44) Karim, A.; Satija, S. K.; Douglas, J . F.; Ankner, J . F.; Fetters, L. J. Phys. Rev. Lett. 1994, 73, 3407.

(45) Milner, S. T.; Witten, T. A.; Cates, M. E. Macromolecules 1988, 21, 2610

(46) Zhulina, E. B.; Borisov, O. V.; Pryamitsyn, V. A.; Birshtein, T. M. Macromolecules 1991, 24, 140.

(47) Lai, P. Y.; Binder, K. J . Chem. Phys. 1992, 97, 586.

(48) Grest, G. S.; Murat, M. Macromolecules 1993, 26, 3108.

(49) Koga, T.; et al. Manuscript in preparation.

(50) Pretel, E.; Rasmussen, A.; Rasmussen, P.; Holten-Andersen, J. Macromolecules 1997, 30, 2775.

MA021265W 